\title{
Comparative characterization of microstrip patch antenna array with defected ground structure for biomedical application
}

\author{
Suganthi Santhanam ${ }^{1}$, Thiruvalar Selvan Palavesam ${ }^{2}$ \\ ${ }^{1}$ Department of Electronics and Communication Engineering, K. Ramakrishnan College of Technology, Tiruchirappalli, Tamilnadu, \\ India \\ ${ }^{2}$ Department of Electronics and Communication Engineering, SRM TRP Engineering College, Tiruchirappalli, Tamilnadu, India
}

\begin{abstract}
Article Info
Article history:

Received Aug 25, 2021

Revised Sep 30, 2021

Accepted Dec 16, 2021

\section{Keywords:}

Biomedical application

Defected ground structure

Flexible substrate

Microstrip patch antenna

Radiation pattern

ABSTRACT

In this paper, microstrip dual band antenna array with defected ground structure has been proposed for low frequency wearable on-body applications. The array has been simulated with Cotton, Polyimide, Polyester and Teflon (PTFE) flexible materials which are mostly used for biomedical applications. The performance of $2 \times 2$ trapezoidal patch array with partial ground, thin slot defection at center has been studied in terms of return loss, VSWR, power handling capability, radiation pattern and surface current distribution. All substrates exhibits acceptable fractional bandwidth below $-10 \mathrm{~dB}$ and Cotton proves its superiority than other substrates with $-20 \mathrm{~dB}$ and $-48 \mathrm{~dB}$ return loss with $16.12 \%$ and $7.73 \%$ bandwidth at $1.24 \mathrm{GHz}$ and $1.94 \mathrm{GHz}$ respectively. The proper matching of array has been proved with VSWR value below 1.3 for all substrates. The observation of input port impedance shows that, Cotton array has good impedance matching nearly to $50 \Omega$ and PTFE array has $100 \Omega$ poor impedance matching. The proposed four flexible array exhibit omnidirectional pattern in $\mathrm{H}$ plane with $1.43 \mathrm{dBi}$ gain and bidirectional pattern in $\mathrm{E}$ plane with $1.4 \mathrm{dBi}$ gain which are support for ideal fitness of proposed flexible material array for medical applications.
\end{abstract}

This is an open access article under the CC BY-SA license.

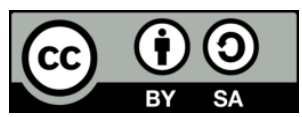

Corresponding Author:

Suganthi Santhanam

Department of Electronics and Communication Engineering

K. Ramakrishnan College of Technology, Tiruchirappalli, Tamilnadu, India

Email: suganthis.ece@krct.ac.in

\section{INTRODUCTION}

Recently the innovation in engineering materials enlarge the flexible electronics for disposable, portable, user friendly and less expensive environment [1]. The need for flexible wireless devices in biomedical applications increases rapidly due to the demand in health monitoring implantable devices [2]. The implantable devices must be conformable and stretchable with human body to integrate for implementation of drug delivery system, intracranial sensors and continuous gait analysis [3]. Several researchers have reported for wearable antenna material, fabrication and application [4]. Some notable literature are related to practical guide for non textile and fully textile wearable antenna design guide [5], flexible printed monopole antenna [6], wearable antenna material from very high frequency (VHF) to $\mathrm{mm}$ band [7], ultra wide band (UWB) antennas for wireless body area network (WBAN) [8], survey of wireless local arear network (WLAN) antenna [9] and flexible antenna [10]. Among the different types of printed antennas for biomedical applications, microstrip patch antenna (MPA) is the most advanced antenna due to the following merits: (1) can be used in various parts of human body since available in various shapes, (2) simple, low profile and inexpensive due to printed fabrication circuit, (3) planar and non planar surface compatibility and robust in mechanical [11], (4) small and light weight and compatible for monolithic 
microwave integrated circuit (MMIC) design, (5) insensitive to human skin, low profile, no cavity backing [12] and conformal in clothing integration. One of the major disadvantages of MPA is substrate layer surface wave excitation [13] which reduces the operating bandwidth, gain and efficiency of antenna. In antenna array, the surface wave plays a vital role in array element mutual coupling [14]. To avoid mutual coupling arrays, electronic band gap (EBG) and defected ground structure (DGS) have been used to improve antenna performance. Array with EBG needs large area for periodic pattern and defining the unit element is difficult. Hence, DGS is mostly preferred in array to control the input impedance and surface current in the ground plane [13].

Photonic band gap (PBG) based DGS was first proposed by Kim et al. for low pass filter and planar circuit application [15]. Different shapes like spiral, dumb bell and circle [16] have reported for DGS in single element microstrip antenna. Recently hexagonal DGS in two element array [17], complementary capacitively loaded loops (CLLs) array [18], DGS with dual frequency patch antenna to reduce mutual coupling [19] are also reported in literature. DGS can also be introduced by slot introduction in resonating patch [20], quarter wave patch [21], truncated corners rectangular patch [22], 2x2 rectangular patch antenna with flexible arm [23], resonant gap or slot in ground plane in 4 x 4 rectangular patch [24].

High gain and minimum return loss microstrip patch antenna and antenna array for biomedical application has been achieved by several authors using different types of substrate. RT duroid DGS antenna with $1.6 \mathrm{~mm}$ thickness at $2.45 \mathrm{GHz}$ [25] and $350 \mathrm{MHz}$ bandwidth for ISM applications, $0.8 \mathrm{~mm}$ thickness FR4 substrate pentagon patch DGS microstrip antenna with -31 dB return loss for good gain of $5.28 \mathrm{dBi}$ [26], $1.52 \mathrm{~mm}$ thickness Taconic substrate square ring resonators patch with $\mathrm{U}$ shaped DGS having $70 \mathrm{MHz}$ bandwidth and $1.5 \mathrm{dBi}$ gain [27] and $0.55 \mathrm{~mm}$ thick Taconic substrate inset fed antenna [28] for industrial scientific medical (ISM) band application are studied for comparison in this paper. The properties of other substrates like Polyimide [29], Polyester [30], PolyTetraFluoroEthylene (PTFE) [31] and Cotton [32] which are utilized for flexible and wearable biomedical application devices fabrication is also reviewed. Recently, 1 x 4 dumb bell DGS microstrip patch antenna array with has been reported for ISM medical application using FR4 [33] which is not flexible for human body injection.

In this paper, the flexible material analysis for the use of substrate in $2 \times 2$ trapezoidal patch microstrip dual-band antenna array has been proposed for the operating frequency for low frequency applications. The most used Cotton, Polyester, Polyimide and PTFE has been used as substrate for the proposed array structure to analyze the return loss, VSWR, impedance matching, power handling capacity, radiation pattern and current distribution. Among the four flexible materials used in this proposal, Cotton substrate array shows suitable properties with low return loss (-19 dB and $-48 \mathrm{~dB}$ at $1.94 \mathrm{GHz})$, VSWR (1.2 and 1.02) closer to ideal value, $50 \mathrm{ohm}$ impedance matching, bidirectional - E - plane and omni - directional $\mathrm{H}$ - plane radiation pattern at $1.24 \mathrm{GHz}$ and $1.94 \mathrm{GHz}$. The presentation of this paper is organized as: in section 2 , the design flow of antenna array with four substrate materials has been discussed. The parameter analysis of proposed antenna array has been reported in section 3 followed by conclusion in section 4 .

\section{ANTENNA DESIGN}

The proposed microstrip patch trapezoidal antenna array (MTAA) with DGS is shown in Figure 1. A thin slot at the center and exactly back to fed point (shown in Figure 1(a)) is etched in half of vertical ground having W/2=1.5 mm size and indicated by white color in Figure 1(b). 2x2 array is achieved by connecting four trapezoidal radiating element at a space of $6.5 \mathrm{~mm}$ from the wall of substrate at four corners as shown in Figure 1(a). The optimized dimensions of array as given in Table 1 is finalized after many trails based on transmission line theory and the final arrived array has the total size of $30 \times 70 \mathrm{~mm}^{2}$ on four different substrates.

Table 1. Optimized dimension (in mm) of proposed MTAA with DGS

\begin{tabular}{cccccccc}
\hline Parameter & Value & Parameter & Value & Parameter & Value & Parameter & Value \\
\hline W & 30 & L & 70 & W2 & 6.5 & W1 & 2.5 \\
Wf & 2 & Lf & 20 & L2 & 7 & L1 & 6 \\
Wp & 10 & Lp & 21 & G & 0.5 & Gl & 14.5 \\
\hline
\end{tabular}

$50 \mathrm{ohm}$ microstrip feed line is used to feed input and DGS is achieved by reducing the background by half and inserting the $0.5 \mathrm{~mm}$ slot exactly at the back of feed point. Initially the array has been tested with FR4 substartes [34] for its basic performance with $-35 \mathrm{~dB}$ retun loss with $-10 \mathrm{~dB}$ bandwidth of $120 \mathrm{MHz}$ at $2.8 \mathrm{GHz}$ resonant frequency. 


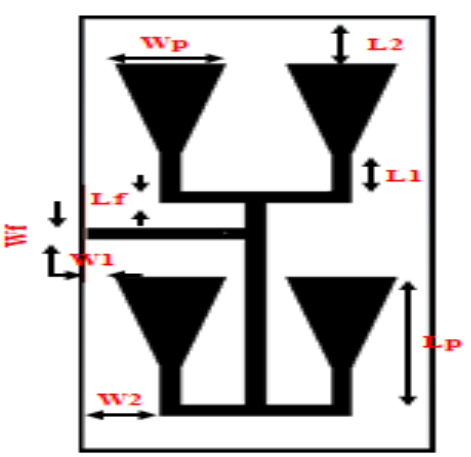

(a)

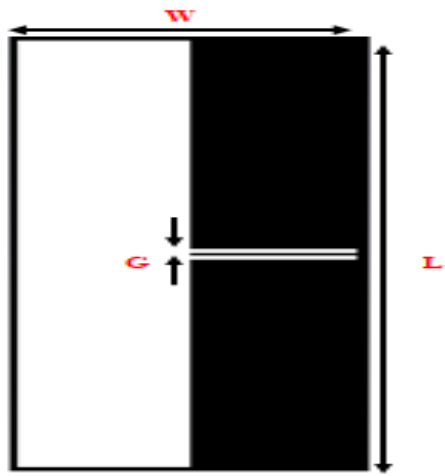

(b)

Figure 1. Structure of proposed microstrip antenna array for four substrate comparison (a) front view and (b) back view

The four substrates used in this paper for peformance comparison of antenna array have been named as in Table 2. The electrical properties, ability to support for medical applications and applications are listed for four substrates. The properties of substartes used in simulation parameters has been taken from Table 2 to compare the performaces in terms of return loss, VSWR, impedance matching, power handling, current distribution and radiation pattern.

Table 2. Proposed flexible array (FA) with DGS in four different substrates with its properties

\begin{tabular}{|c|c|c|c|c|c|c|}
\hline \multirow[b]{2}{*}{$\begin{array}{l}\text { Antenna } \\
\text { Name }\end{array}$} & \multicolumn{6}{|c|}{ Substrate } \\
\hline & Name & $\begin{array}{c}\text { Thickness } \\
(\mathrm{mm})\end{array}$ & $\begin{array}{c}\text { Loss } \\
\text { tangent }\end{array}$ & $\begin{array}{c}\text { Dielectric } \\
\text { constant }(\mathrm{mm})\end{array}$ & Ability & Applications \\
\hline FAPM & Polyimide & 0.2 & 0.005 & 2.91 & $\begin{array}{l}\text { Biocompatibility, flexibility, high } \\
\text { tensile strength }\end{array}$ & drug delivery systems \\
\hline FAPE & Polyester & 1.6 & 0.02 & 2.8 & $\begin{array}{l}\text { Minimal risks of toxicity, } \\
\text { immunogenicity and infection. }\end{array}$ & Drug delivery system \\
\hline FAPT & $\begin{array}{l}\text { Teflon } \\
\text { (PTFE) }\end{array}$ & 2 & 0.0028 & 2.1 & $\begin{array}{l}\text { Use for internal body fluid \& tissue } \\
\text { contact without explicit consent. }\end{array}$ & On body \\
\hline FACT & Cotton & 2.8 & 0.02 & 1.6 & Soft, absorbent and hypoallergenic & $\begin{array}{l}\text { Non-implantable } \\
\text { products }\end{array}$ \\
\hline
\end{tabular}

\section{RESULTS AND DISCUSSION}

A trapezoidal patch microstrip feed $30 \times 70 \mathrm{~mm}^{2}$ antenna array with partial ground slot based DGS is designed with four flexible substrates and simulated using electromagnetic solver from $1 \mathrm{GHz}$ to $3 \mathrm{GHz}$. The simulated results are summarized for return loss, VSWR, radiation pattern and current distribution.

\subsection{Return loss}

$10 \mathrm{~dB}$ return loss which is the percentage of energy emitted from the array shows dual band for all four substrates. From the comparison of $S_{11}$ of array with four substrates as in Figure 2(a), it is noted that FACT has $-20 \mathrm{~dB}$ and $-48 \mathrm{~dB}$ with $16.12 \%$ and $7.73 \%$ impedance bandwidth compared to $-17 \mathrm{~dB}$ and $-18 \mathrm{~dB}$ along $13.7 \%$ and $6.9 \%$ by FAPM, $-17 \mathrm{~dB}$ and $-23 \mathrm{~dB}$ along $9.2 \%$ and $6.7 \%$ by FAPE and $-19 \mathrm{~dB}$ and $-20 \mathrm{~dB}$ along $14.5 \%$ and $6.5 \%$ by FAPT at $1.2 \mathrm{GHz}$ and $1.9 \mathrm{GHz}$ dual band. Comparing among four loss plots, though there is no much difference in return loss at $1.24 \mathrm{GHz}$ first band, the FACT shows vast variations in its loss characteristics at $1.94 \mathrm{GHz}$ compared to others substrates arrays. The Polyester substrates shift towards left in second resonant at $1.75 \mathrm{GHz}$ compared to other substrates which maintain the second resonant at $1.94 \mathrm{GHz}$. Reflection characteristics analysis conform that, Cotton array shows better performance with lower return loss at $1.24 \mathrm{GHz}$ and $1.94 \mathrm{GHz}$ with better impedance property compared with other substrates arrays. Our proposed array performs in dual band with better impedance bandwidth compared to low cost non flexible FR4 substrate.

\subsection{VSWR}

Voltage standing wave ratio is the other property of antennas to show its idealness in terms of impedance matching and power handling capability. The proposed array attains VSWR very close to 1 which 
is typical and ideal value to prove its effectiveness at both operating frequency. In this property also, Cotton substrate array shows ideal performance with 1.32 and 1.08 values at $1.2 \mathrm{GHz}$ and $1.9 \mathrm{GHz}$ as shown in Figure 2(b) compared to other material arrays. The other substrates VSWR also falls under this region within the values of 2 and proves the idleness for medical applications.

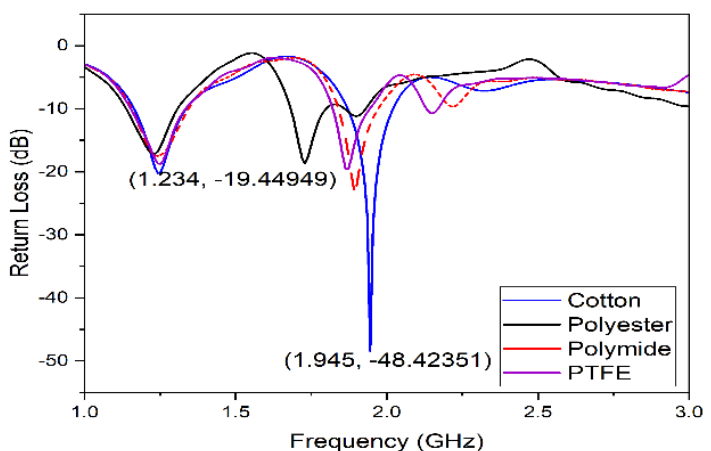

(a)

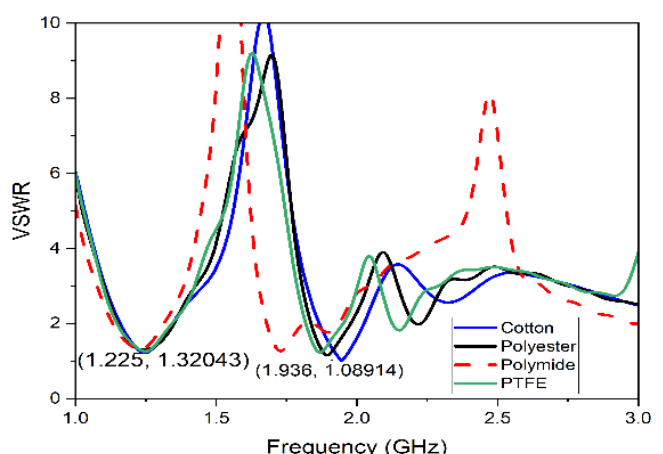

(b)

Figure 2. Comparative analysis of proposed array with four substrates (a) return loss and (b) VSWR

\subsection{Impedance matching $\&$ power handling}

Generally, in radio frequency antenna, for maximum power transmission, the input and output impedances are considered as main design parameters to avoid return loss due to mismatching between the two points in contact. The input impedance property of antenna used in medical applications is essential technical parameter to improve the efficiency of devices by reducing the loss due to reflection. To confirm the minimization of loss for the proposed antenna array, the impedance matching at feed point is verified for four materials and the comparison is shown in the Figure 3. The variation in impedance is considerable level in array with Polyester and array with other material shows that the input impedance is very closer to ideal $50 \mathrm{ohm}$ value. As depicted in Figure 3(a), both at $1.24 \mathrm{GHz}$ and $1.94 \mathrm{GHz}$, the Cotton substrate array matches with $50 \mathrm{ohm}$ impedance and is not achieved in other material array having impedance variation even upto $100 \mathrm{ohm}$. This confirms the superior performance of Cotton substrate rather than other materials. The impedance matching is verified in terms of power accepted at input port and outgoing power at other output ports. In CST software, the input power spectrum is averaged in time domain for the period at every frequency as shown in Figure 3(b).

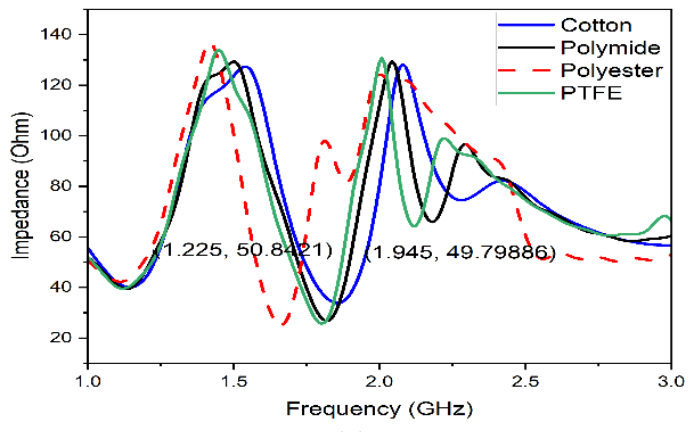

(a)

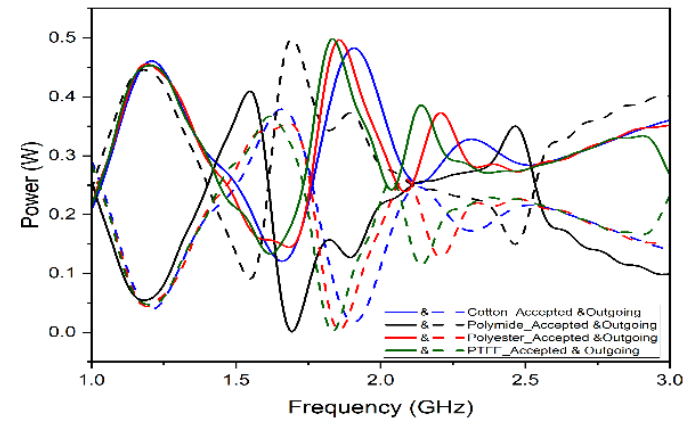

(b)

Figure 3. Parametric comparison of array with four substrates (a) input impedance and (b) power accepted at input ports and outgoing at all output ports

This input power is used as the feed point excitation to this dual band antenna and is applied separately with 0.5 watt at each frequency. The Figure 3(b) shows the comparison of net power accepted by the array presented as power accepted and the total power reflected by the array to the feed point as power outgoing. The peak to peak amplitude of input power accepted and output power is same with $180^{\circ}$ phase 
shift for four flexible materials MTAA. This ensures the minimum insertion and absorption loss in the proposed structure for biomedical applications.

\subsection{Radiation pattern}

The simulated radiation pattern at dual frequency for $\mathrm{E}$ plane and $\mathrm{H}$ plane for four substrate materials MTAA has been compared in Figure 4. At $1.24 \mathrm{GHz}$ as in Figure 4(a) for x-z, azimuth or E plane simulated radiation pattern, it is observed that FACT provides a gain of $1.43 \mathrm{dBi}$ in $88^{\circ}$ beamwidth with phi $=90^{\circ}$. FAPT, FAPE and FAPM array provides $1.31 \mathrm{dBi}, 1.24 \mathrm{dBi}$ and $1.22 \mathrm{dBi}$ gain respectively. In $\mathrm{x}-\mathrm{y}$, elevation or $\mathrm{H}$ plane, the Cotton array provides $1.4 \mathrm{dBi}$ gain with main lobe direction at $174^{\circ}$ compared to $1.29 \mathrm{dBi}$ with $176^{\circ}$ for FAPT, $1.22 \mathrm{dBi}$ at $179^{\circ}$ for $\mathrm{FAPE}$ and $1.2 \mathrm{dBi}$ at $175^{\circ}$ for $\mathrm{FAPH}$ array for phi $=0^{\circ}$ as shown in Figure 4(b).

From the radiation pattern figures, it is clear that proposed antenna array with four flexible substrate provides bidirectional pattern in $\mathrm{E}$ plane with eight shape in $2 \mathrm{D}$ and unidirectional radiation in $\mathrm{H}$ plane. These ideal patterns are disturbed in all four cases at $1.94 \mathrm{GHz}$ as in Figure 4(b). The gain is reduced with side lobe of $0.9 \mathrm{~dB}$ for Cotton array and Polyimide array provides $1.15 \mathrm{dBi}$ at $178^{\circ}$ with $94.3^{\circ}, 3 \mathrm{~dB}$ beam width. Polyester material deliver $1.13 \mathrm{dBi}$ gain at $179^{\circ}$ with $87.2^{\circ}$ beam width and side lobe level of $1 \mathrm{~dB}$. In $\mathrm{H}$ plane, at $1.94 \mathrm{GHz}, 1.2 \mathrm{dBi}, 1.12 \mathrm{dBi}$ and $1.22 \mathrm{dBi}$ gain values achieved from Polyimide, Polyester and Teflon array respectively as shown in Figure 4(c) and (d).

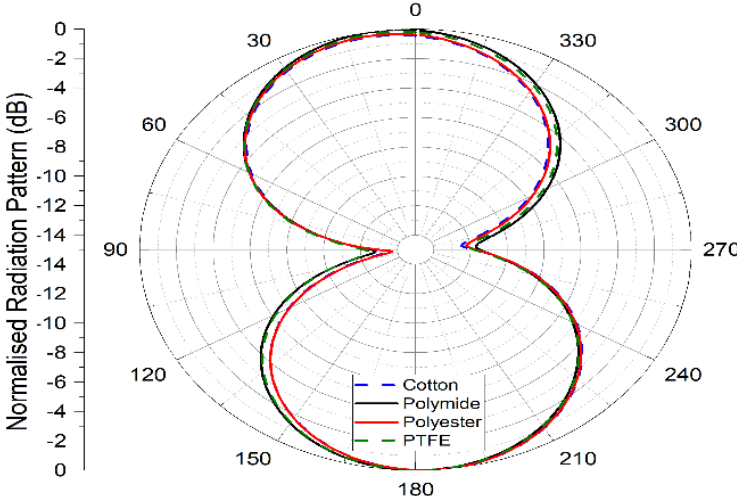

(a)

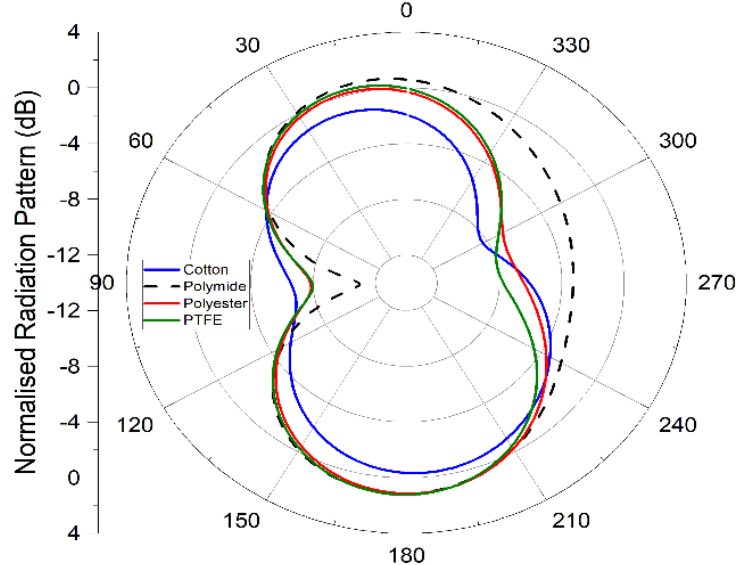

(c)

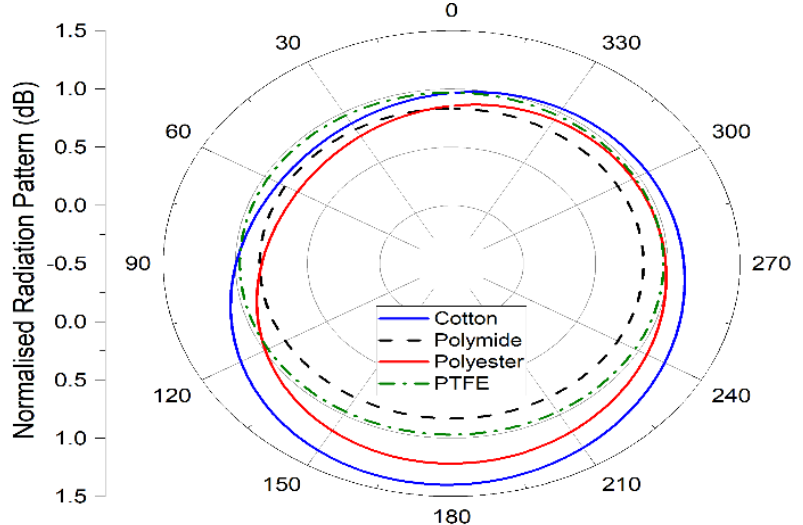

(b)

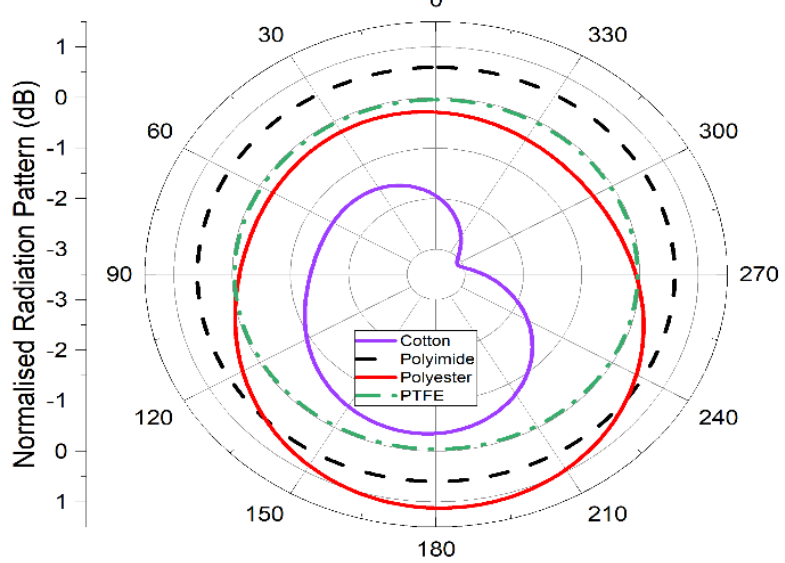

(d)

Figure 4. Comparison of far field radiation pattern of MTAA with Cotton, Polyimide, Polyester and Teflon substrate at $1.24 \mathrm{GHz}$; (a) azimuth or E plane, (b) elevation or $\mathrm{H}$ plane and comparison of pattern at $1.94 \mathrm{GHz},(\mathrm{c})$ azimuth or E plane, and (d) elevation or $\mathrm{H}$ plane

\subsection{Surface current}

The current density of the antenna array is analyzed for four substrates and the current distribution for Cotton array is plotted in Figure 5. At $1.24 \mathrm{GHz}$, the density is high at $45.3 \mathrm{~A} / \mathrm{m}$ in Polyester array 
compared to $42.3 \mathrm{~A} / \mathrm{m}, 41.4 \mathrm{~A} / \mathrm{m}$ and $36.7 \mathrm{~A} / \mathrm{m}$ density for Polyimide, Teflon and Cotton array (Figure 5(a)) respectively. But at $1.94 \mathrm{GHz}$, this distribution shows higher density for Cotton array with $128 \mathrm{~A} / \mathrm{m}$ level compared to $98.3 \mathrm{~A} / \mathrm{m}, 86.3 \mathrm{~A} / \mathrm{m}$ and 7.2 A/m for Polyester, Teflon and Polyimide array respectively.

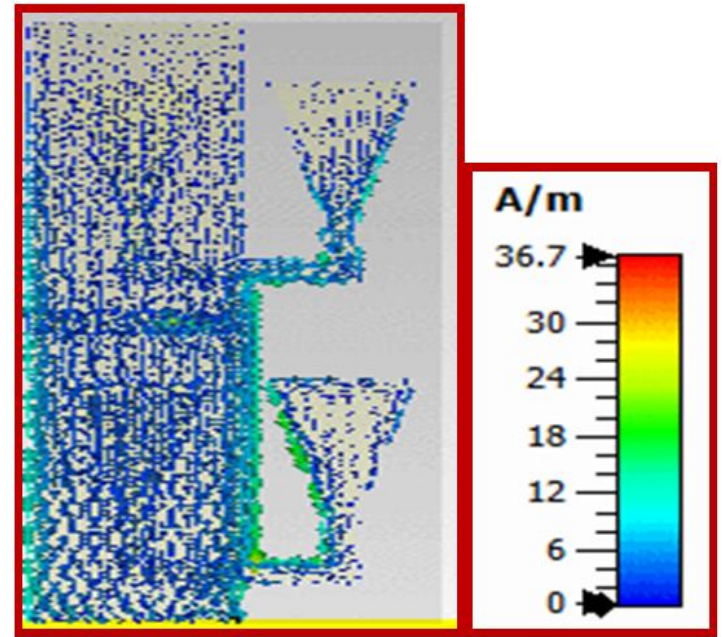

(a)

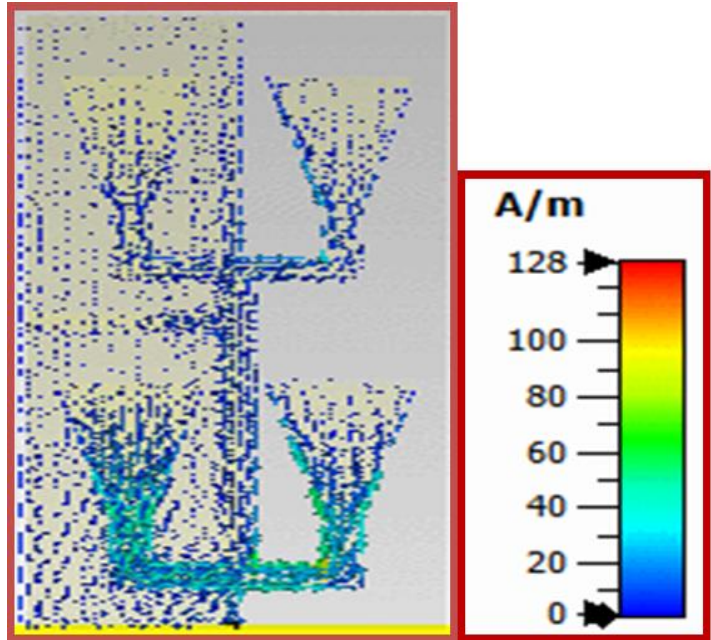

(b)

Figure 5. Current distribution in Cotton array at (a) $1.24 \mathrm{GHz}$ and (b) $1.94 \mathrm{GHz}$

Table 3 shows the performance comparison of proposed array with the similar antenna array reported in references. It is depicted that our proposal attain higher impedance bandwidth at both the resonant compared to other antennas without the compensation in size. The Cotton substrate array proves efficient with $170 \mathrm{MHz}$ and $330 \mathrm{MHz}$ bandwidth at $1.24 \mathrm{GHz}$ and $1.94 \mathrm{GHz}$ which can be used for wide band medical disgonosis applications in $\mathrm{L}$ - band at 1-2 GHz.

Table3. Comparison of our flexible array with others in literature (NS: not stated)

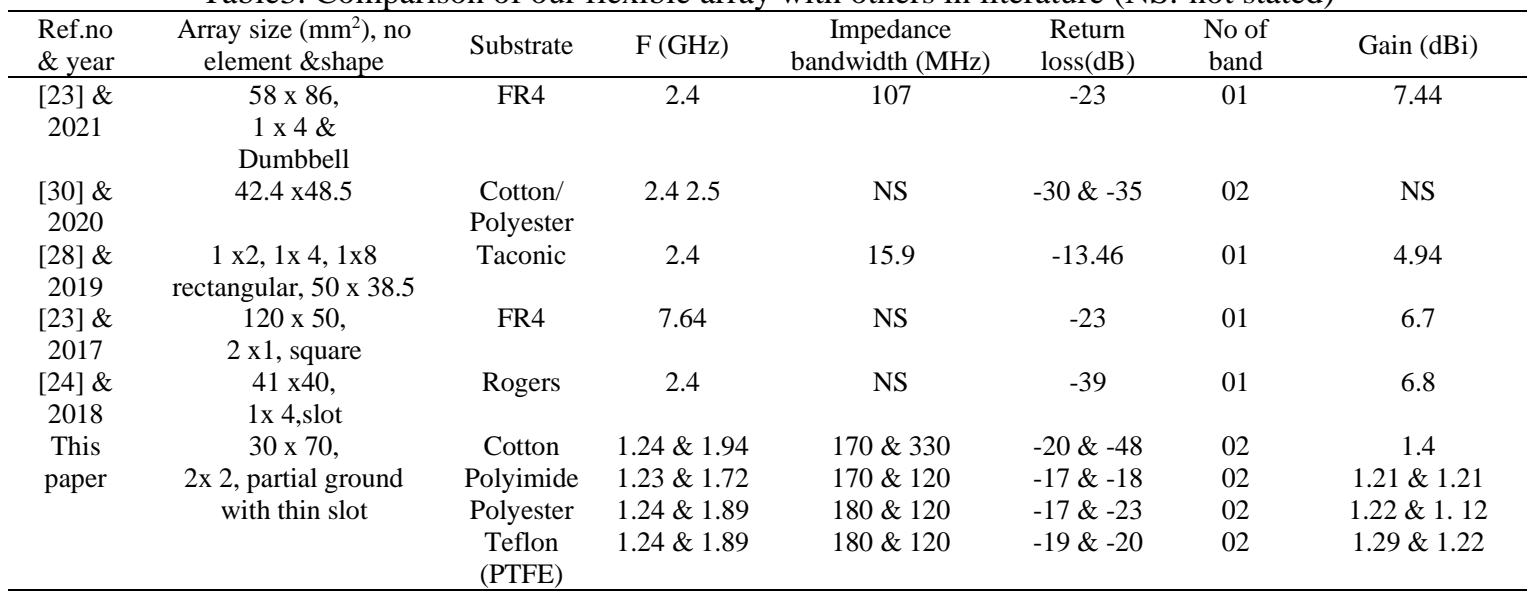

\section{CONCLUSION}

The $2 \times 2$ trapezoidal micrstrip dual band antenna array having DGS with four flexible substrate materials has been designed successfully and electrical parameters in terms of return loss, VSWR, input impedance, power handling capability, radiation pattern and current density are compared. The proposed array has low loss profile up to-48 dB with 1.02 VSWR, no power absorption with $50 \Omega$ input impedance, ideal eight shape bidirectional $\mathrm{E}$ plane and omnidirectional $\mathrm{H}$ plane radiation pattern. Out of four flexible material array studied, Cotton array proves the better performance in lower loss, impedance matching, better fractional bandwidth, high gain of $1.4 \mathrm{dBi}$ with lower side lobe of $1 \mathrm{~dB}$ in $\mathrm{E}$ plane eight shape bidirectional and $\mathrm{H}$ plane omnidirectional pattern in both $1.24 \mathrm{GHz}$ and $1.94 \mathrm{GHz}$ resonant frequency. The proposed low 
frequency dual band flexible material array can be used for study of structural biology and intrinsically disordered proteins, capsule endoscope communications, in body transmitter, noninvasive sensing and imaging techniques and wireless telehealth systems.

\section{REFERENCES}

[1] S. G. Kirtania et al., "Flexible antennas: A review," Micromachines, vol.11, no.847, pp.1-43, 2020, doi: 10.3390/mi11090847.

[2] P. Sethi and S. R. Sarangi, "Internet of things: Architectures, Protocols and Applications," Journal of Electronics Computer Engineeering, vol. 2017, pp. 1-25, 2017, doi: 10.1155/2017/9324035.

[3] S. F. Jilani, Q. H. Abbasi and A. Alomainy, "Inkjet-Printed Millimetre-Wave PET-Based Flexible Antenna for 5G Wireless Applications," IEEE MTT-S International Microwave Workshop Series on 5G Hardware and System Technologies (IMWS-5G), 2018, pp. 1-3, doi: 10.1109/IMWS-5G.2018.8484603.

[4] J. Deepa, S. Suganthi, G. S. Ranjani, J. C. Freeda and M. Jayaprabha, "Multiband Planar MIMO Antenna for GSM1800/LTE2300/WiMAX/WLAN Applications," International Journal of Engineering Research \& Technology, vol. 4. no. 19. pp. 38-43, 2016.

[5] A. Ghasemi and E. S. Sousa, "Spectrum sensing in cognitive radio networks: requirements, challenges and design trade-offs," IEEE Communications Magazine, vol. 46, no. 4, pp. 32-39, 2008, doi: 10.1109/MCOM.2008.4481338.

[6] R. Singh, E. Singh and H. S. Nalwa, "Inkjet printed nano material based flexible radio frequency identification (RFID) tag sensors for the internet of nano things," RSC Adv, vol. 7, no. 77, pp. 48597-48630, 2015, doi: 10.1039/C7RA07191D.

[7] V. K. Abhinav, V. K. R. Rao, P. S. Karthik and S. P. Singh, "Copper conductive inks: Synthesis and utilization in flexible electronics," RSV Adv, vol. 5, no. 79, pp. 63985-64030, 2015, doi: 10.1039/c5ra08205f.

[8] S. Masihi et al., "Development of a Flexible Tunable and Compact Microstrip Antenna via Laser Assisted Patterning of Copper Film," IEEE Sensors Journal, vol. 20, no. 14, pp. 7579-7587, 2020, doi: 10.1109/JSEN.2020.2987318.

[9] S. Suganthi and P. T. Selvan, "Defected Ground Micro strip Patch Antenna for WLAN applications," International Journal of Innovative Technology and Exploring Engineering, vol.08, no.09, pp:1575-1579, 2019. doi: 10.35940/ijitee.I7882.078919

[10] R. S. Sangam, S. Ploolakkal, R. Palthiya and N. Nallam, "Dual port aperture coupled tapered fed patch antenna for full duplex ISM applications," Microwave optical technology letter, vol. 61, no. 2, pp. 542-545, 2019, doi: 10.1002/mop.31593.

[11] M. J. Jeong, N. Hussain, J. W. Park, S. G. Park, S. Y. Rhee and N. Kim, "Millimeter wave microstrip patch antenna using vertically coupled split ring metaplate for gain enhancement," Microwave optical technology letter, vol. 61, no. 10, pp. 2360-2365, 2019, doi: 10.1002/mop.31908.

[12] S. Sankaralingam and B. Gupta, "Determination of Dielectric Constant of Fabric Materials and Their Use as Substrates for Design and Development of Antennas for Wearable Applications," IEEE Transactions on Instrumentation and Measurement, vol. 59, no. 12, pp. 3122-3130, 2010, doi: 10.1109/TIM.2010.2063090.

[13] F. Y. Zulkifli, E. T. Rahardjo and D. Hartanto, "Radiation properties enhancement of triangular patch microstrip antenna array using hexagonal defected ground structure," Progress In Electromagnetics Research M, vol. 5, pp. 101-109,2008, doi: 10.2528/PIERM08101601.

[14] R. Gang, P. Bhartia and I. J. Bahl, "Microstrip antenna design handbook," Artech House, Boston, London, 2001.

[15] C. S. Kim, J. S. Park, D. Ahn and J. B. Lim, "A novel 1D periodic defected ground structures for planer circuits," IEEE Microwave guided wave Lett., vol. 10, no. 4, pp. 131-133. 2000

[16] S. L. Mallikarjun, P. M. Hadalgi and P. V. Hunagund, "Study of effect of rectangular DMS and DGS on 4 and 8 elements rectangular microstrip linear array antenna," Journal of Microwaves, Optoelectronics and Electromagnetic Applications, vol. 10, no. 1, pp. 13-23, 2011, 10.1590/S2179-10742011000100002.

[17] S. K. Jose and S. Suganthi, "Circular rectangular microstrip antenna for wireless apllications," International Journal of Microwaves Applications, vol. 4, no. 1, pp. 6-10, 2015.

[18] P. N. Fletcher, M. Dean and A. R. Zix, "Mutual coupling in multi element array antennas and its influence on MIMO channel capacity," Electronics Letters, vol. 39. no. 4, pp. 342-344, 2003, doi: 10.1049/el:20030219.

[19] Y. Yu, L. Yi. Y. Liu, Z. Gu and N. M. Rizka, "Dual frequency two element antenna array with suppressed mutual coupling," International Journal of Antennas and propagation, vol. 2015, Art. Id. 912934, pp.1-6, 2014, doi: 10.1155/2015/912934.

[20] S. A. Bokhari, J. Zurcher, J. R. Mosig and F. E. Gardiol, "A small microstrip patch antenna with a convenient tuning option," IEEE Transactions on Antennas and Propagation, vol. 44, no. 11, pp. 1521-1528, 1996, doi: 10.1109/8.542077.

[21] R. Chair, K. M. Luk and K. F. Lee, "Miniature multi layer shorted patch antenna,” Electronics Letters, vol. 36, pp. 3-4, 2000, doi: 10.1049/el:20000029.

[22] O. Oulhaj, T. N. Touhami, M. Aghoutane and T. P. Antonio, "A miniature microstrip patch antenna array with defected ground structure," International Journal of Microwave and Optical Technology, vol. 11, no. 1, pp. 32-39, 2016.

[23] S. R. Mishra and K. L. Sheeja, "DGS inspired microstrip antenna array for improved radiation properties," International Journal of Engineering and Techniques, vol. 3, no. 1, pp. 38-42, 2017.

[24] N. Sharma and Jyoti, "Design of four element array based antenna with defected ground structure to improve gain and return loss," Internasional Journalof Innovative Science English and Technology, vol. 5, no. 10, pp. 7-11, 2018.

[25] T. V. Hoang, T. T. Le, Q. Y. Li and H. C. Park, "Quad-Band Circularly Polarized Antenna for 2.4/5.3/5.8-GHz WLAN and 3.5GHz WiMAX Applications," IEEE Antennas and Wireless Propagation Letters, vol. 15, pp. 1032-1035, 2016, doi: 10.1109/LAWP.2015.2490258.

[26] R. Raihan, M. S. A. Bhuiyan, R. R. Hasan, T. Chowdhury and R. Farhin, "A wearable microstrip patch antenna for detecting brain cancer," IEEE 2nd International Conference on Signal and Image Processing (ICSIP), 2017, pp. 432-436, doi: 10.1109/SIPROCESS.2017.8124578

[27] R. Patel, A. Desai, and T. K. Upadhyaya, "An electrically small antenna using defected ground structure for RFID, GPS and IEEE 802.11 A/B/G/S/ applications," Progress in Electromagnetics Research, vol. 75, pp. 75-81, 2018, doi: 10.2528/PIERL18021901

[28] M. S. Islam, M. Ibrahimy, S. M. A. Motakabber, A. K. M. Hossain, and S. M. K. Azam, "Microstrip patch antenna with defected ground structure for biomedical application," Bulletin of Electrical Engineering and Informatics, vol. 8, no. 2, pp. 586-595, 2019, doi: 10.11591/eei.v8i2.1495.

[29] H. R. Khaleel, H. M. Al-Rizzo, D. G. Rucker and S. Mohan, "A Compact Polyimide-Based UWB Antenna for Flexible Electronics,” IEEE Antennas and Wireless Propagation Letters, vol. 11, pp. 564-567, 2012, doi: 10.1109/LAWP.2012.2199956. 
[30] S. M. Ali, C. Sovuthy, M. A. Imran, S. Socheatra, Q. H. Abbasi and Z. Z. Abidin, "Recent advances of wearable antenna in materials, fabrication methods, designs and their applications: state of art," Micromachines, vol. 11, no. 10, pp. 1-41, 2020, doi: 10.3390/mi11100888.

[31] R. Sreelakshmyand G. Vairavel, "Novel Cottonantenna for dual band applications," ICT express, vol. 5, pp. 26-30, 2019, doi: $10.1016 /$ j.icte.

[32] W. G. Whittow et al., "Inkjet-Printed Microstrip Patch Antennas Realized on Textile for Wearable Applications," IEEE Antennas and Wireless Propagation Letters, vol. 13, pp. 71-74, 2014, doi: 10.1109/LAWP.2013.2295942.

[33] S. Dharmpatre and Mukulsutaone, "Design and characterization analysis of microstrip patch array antenna with dumbbell shaped DSG for Ism band applications," Turkish Journal of Computer and Mathematics Education, vol. 12, no. 9, pp. 2652-2663, 2021, doi: 10.17762/turcomat.v12i9.3984

[34] S. Suganthi and T. S. Palavesam, "Microstrip feed trapezoidal shape antenna array with defected ground structure for S band applications," International Journal of Engineering and Advanced Technology, vol. 10, no. 5, pp. 279-284, 2021, doi: 10.35940/ijeat.D2497.0610521

\section{BIOGRAPHIES OF AUTHORS}

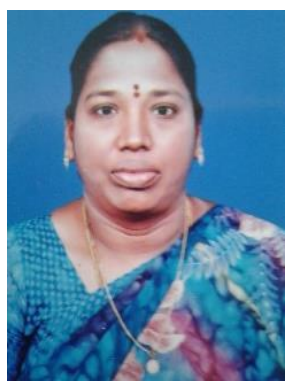

Suganthi Santhanam (D) 81 SC P received the B.E degree in Electronics and Communication Engineering from Bharathidasan University, Thiruchirappalli, Tamilnadu, India in 1998 and the M.E. degree in computer and communication from the Anna University, Chennai, Tamilnadu, India, in 2006 and Ph.D (RF MEMS) from Anna University Chennai. She is currently a Professor with the Department of Electronics and Communication Engineering, $\mathrm{K}$. Ramakrishnan College of Technology, Tamilnadu, India. Her research interests include ANN's, digital signal processing, MATLAB, CAD of VLSI circuits, computer-aided design methodologies for microwave modeling techniques. She can be contacted at email: suganthis.ece@krct.ac.in

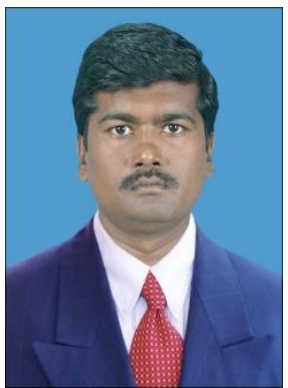

Thiruvalar Selvan Palavesam (iD 8 SC SC was born in 1974 in Tenkasi, Tamilnadu, India. He completed his Diploma in Electronics and Communication in 1992 and received graduate Engineers in 2001 at The Institution of Engineers (INDIA) and completed his Ph.D in Microwave in 2011 from National Institute of Technology, Trichy. In 2004 he received the M.E. degree in computer and communication from Anna University, Chennai, India. He was with the department of Electronics and Communication, Polytechnic, Tenkasi as an Instructor from 1992 to 1999 and then as an Assistant Professor in Engineering College from 2001 to 2007. He is currently working as Professor in SRM TRP Engineering College, Trichy. His research interest includes neural networks, modeling and their applications in CAD for microwave devices and circuits. He can be contacted at email: tvsbalashakil@gmail.com 